\title{
Investigating Male Presence at Antenatal and Choice of Place for Child Delivery in Ghana
}

\author{
Phidelia Theresa Doegah* \\ Institute of Health Research, University of Health and Allied Sciences, Ho, Ghana
}

Male involvement in maternal health was introduced to improve and sustain maternal and child health in Ghana. The study utilized the 2014 Ghana Demographic and Health Survey data to investigate the relationship between male presence at antenatal and choice of place of childbirth among 1,167 males, 15-59 years. Descriptive and analytical statistical techniques were applied to the data. The binary logistic regression shows no association between male presence at antenatal and place of delivery $(\mathrm{OR}=1.197$; $95 \% \mathrm{Cl}=0.808-1.773)$. However, age $(\mathrm{OR}=2.647 ; 95 \% \mathrm{Cl}=1.221-5.736$, $\mathrm{OR}=3.046 ; 95 \% \mathrm{Cl}=1.345-6.896, \mathrm{OR}=3.513 ; 95 \% \mathrm{Cl}=1.478-8.345)$, level of education $(\mathrm{OR}=4.478 ; 95 \% \mathrm{Cl}=1.412-14.1990$, religion $(\mathrm{OR}=0.473 ; 95 \%$

OPEN ACCESS

Edited by:

Vesna Bjegovic-Mikanovic, University of Belgrade, Serbia

Reviewed by: Lawrence Ulu Ogbonnaya, Federal Teaching Hospital Abakaliki, Nigeria Afolaranmi Olumide Tolulope, Jos University Teaching Hospital, Nigeria

*Correspondence: Phidelia Theresa Doegah tdoegah@uhas.edu.gh

Specialty section: This article was submitted to Public Health Policy,

a section of the journal

Frontiers in Public Health

Received: 14 April 2019 Accepted: 04 October 2019 Published: 22 October 2019

Citation:

Doegah PT (2019) Investigating Male Presence at Antenatal and Choice of Place for Child Delivery in Ghana. Front. Public Health 7:300. doi: 10.3389/fpubh.2019.00300
$\mathrm{Cl}=0.237-0.946)$, ethnicity $(\mathrm{OR}=0.400 ; 95 \% \mathrm{Cl}=0.182-0.877, \mathrm{OR}=0.425 ; 95 \%$ $\mathrm{Cl} 0.194-0.935)$, marital status $(\mathrm{OR}=5.682 ; 95 \% \mathrm{Cl}=2.093-15.421$, $\mathrm{OR}=5.669$; $95 \% \mathrm{Cl}=1.448-22.198)$, place of residence $(\mathrm{OR}=7.272 ; 95 \% \mathrm{Cl}=4.231-12.499)$, and region of residence $(\mathrm{OR}=11.515 ; 95 \% \mathrm{Cl}=2.785-47.618)$ of males were found associated with health facility based delivery. Regarding policy to promote institutional delivery among women, these socio-demographic factors identified should be considered.

Keywords: maternal health, male presence, antenatal, place of delivery, Ghana

\section{INTRODUCTION}

In 2015, about 303,000 women were reported to have died from pregnancy and childbirth around the world. The majority of these deaths were noted to occur in developing countries (1). Global efforts to reduce maternal mortality rate (MMR) by $<70 \%$ in 2030 are embodied in the sustainable development goal (SDG) number 3. Ghana, following global efforts, also had in place several strategies in a bid to save the lives of mothers and children. Strategies include, among others, the launch of free antenatal and delivery care for pregnant women, Safe-Motherhood initiative, Prevention of Maternal Mortality Program (PMMP), Maternal and Neonatal Health Program, and Making Pregnancy Safer Initiative. However, the MMR was reducing at a slow pace and thus Ghana missed out on the 2015 millennium development goal (MDG) to reduce MMR by 75\% (2).

Ghana's Ministry of Health $(\mathrm{MoH})$, together with the United Nations Fund for Population Activities (UNFPA), realized the dominance of males in the Ghanaian context, and introduced the concept of male involvement in order to promote family planning, gender equality, and maternal and child health (3). In the African setting, the man is the head of the house and is largely responsible for all decision making, or every decision is approved by him, as most husbands are financially more empowered in comparison to their wives. As such, there is the need to involve 
them in maternal issues if women are to patronize the services. For instance, in studies on male involvement in family planning, scholars found among Nigerian males in Ile-Ife Osun State that their poor involvement in family planning (FP) decision resulted in low use of FP services [(4), p. 49]. Additionally, a study in Tanzania found that women in male headed households usually deliver out of health facilities [(5), p. 867-868]. There is a consensus that when males know and can identify symptoms related to pregnancy complications then they are able to act upon the knowledge and seek skilled care for the woman [(6), p. 33].

Antenatal care (ANC) and use of skilled birth attendants are essential to reduce maternal mortality $(\mathrm{MM})$ as complications can be detected during these visits by the skilled attendants. However, in Ghana, recognizing the critical signs and knowing what to do are usually part of the ANC session for the pregnant women, and thus the need for males to be present for spouse's ANC arises. Positive male involvement in maternal health then refers to the mental and physical participation of males in maternal and prenatal health and family planning in such a way as to increase maternal and fetal survival rates (7).

Pregnancy or child bearing from anecdotal sources has been regarded solely as a woman's duty, as such studies have focused largely on background characteristics of women such as age, educational level [(8), p. 6]; place of residence [(8), p. 7]; and occupational status [(5), p. 865]. It is generally assumed that the use of maternal healthcare services such as the choice of place to deliver is dependent on the woman. Due to this assumption, there has been less research on male involvement in maternal health.

As observed, fewer studies to date have investigated whether male presence at ANC culminated into choice of health facility for child delivery using the Ghanaian population. Results of this relationship would be vital for policy to promote the utilization of maternal healthcare services to increase maternal and fetal survival. Using the Ghana Demographic and Health Survey (GDHS) 2014 data, this study sought to determine whether male presence at ANC determines choice of place of child delivery.

Nevertheless, individual male socio-demographic characteristics could also predict the place of children's birth and these were included as a control for anticipated male presence effects. A study has found that a man's background characteristics also play a role in a woman's choice of place [(9), p. 103]. For instance, a husband's level of education was found to be associated with wives' use of maternal health care services in Nigeria and Ghana respectively $[(10,11)$, p. 3]; also, rural residences of males were found to be associated with lower participation in maternal healthcare [(12), p. 153]. However, Danforth et al. [(13), p. 701]; Carter and Speizer [(12), p. 153] observed no association between a woman's use of maternal services and her husband's level of education amongst a sample of women in Tanzania. Also associated with maternal healthcare use is the region of the residence of males (10). This research seeks to address the following research questions: does a male presence at ANC result in the choice of health facility for child delivery? What male socio-demographic factors are associated with the choice of health facility for child delivery controlling for male presence at ANC?

\section{MATERIALS AND METHODS}

Data for this study are from the 2014 Ghana Demographic and Health Survey (GDHS). The GDHS (14) is a household-based survey with a probability sample of 12,831 households selected nationwide and stratified by region and residence. It employed a two-stage sampling design where the first stage involved selecting sample points or clusters from an updated master sampling frame constructed from the 2010 Ghana Population and Housing Census. A total of 427 clusters were selected from the master sampling frame. The clusters were selected using systematic sampling with probability proportional to size. The second stage of selection involved the systematic sampling of 30 of the households listed in each cluster.

Three questionnaires were used in all: the Household, the Women's, and the Men's Questionnaires. The Men's Questionnaire was administered to all men aged 15-59 living in half of the selected households in the GDHS sample. A sample of 1,139 (1,167 un-weighted sample) males was extracted for this study through two stages. At the first instance, respondents with missing cases on variable mv250 (place of birth of most recent child) were dropped, a total of 3,178 observations. Secondly, respondents with missing data for mv249 (respondent present during check-ups for most recent child) were also dropped (total of 43 observations dropped), and thus arrived at the final sample size. To ensure representativeness and correct non-responses, the data is weighted taking into consideration the complex survey design, using the "svyset" command in Stata. The survey set is adjusting for complex survey, cluster, strata, and weight variable. The variables required for the "svyset" is the wtvar (weight variable), Primary Sampling Unit (PSU), and Strata. The "svyset" command used in Stata for this study is svyset [pw=wtvar], psu (mv021) strata (mv023).

The independent variable for the study is male presence at antenatal (if man was present during wife's antenatal for most recent child [Yes/No]) and the outcome variable is the choice of delivery place of child ("Was [NAME] born in a hospital or health facility?" the responses were hospital/health facility or other). For the outcome variable, the "health facility" response was re-coded " 1 " and "Other" re-coded " 0 ." The "Other" option entails any place other than a health facility.

Ghana Statistical Service (GSS) the institution responsible for the GDHS data collection obtained ethical clearance from the relevant Institutional Review Boards (IRBs) and consent from the eligible respondents.

\section{Data Analysis}

Variables were explored with the use of descriptive statistics (frequencies and percentages). Bivariate analysis (cross tabulations) was carried out to examine the variations in the study sample regarding place of delivery of child and explanatory variables. The Chi-Square test statistic was used to assess the significance between background variables and place of delivery. Significance was set at 0.05. To examine the influence of male presence on place of delivery a binary logistic regression was fitted. The model results were interpreted using the odds ratio (OR) and the _hatsq (hat square) value was used 
to determine a well-specified model. All analyses were conducted using Stata version 12.0.

\section{RESULTS}

In Table 1, generally more than half (56\%) of males indicated absenteeism during spouses' ANC attendance. Results show that a higher proportion (40\%) of men belonged to the 25-34 age group whilst the age group 15-24 had the least proportion. More than a half of the sample had attained a Senior Secondary School level with the least proportion with a higher education. More than three-fifth (66\%) of the men are Christians, followed by males who are Muslim, whilst a lesser proportion belonged to the "Other" religious group. A higher proportion of the sample is made up of Akan, Mole-Dagbani and "Other" accordingly. Males' in-union constituted the most, whilst the least proportion is formerly married. A greater number of the men reside in rural areas. In terms of region of residence, a higher proportion of males in the study sample dwell in the Greater Accra region followed by Ashanti region whilst the least stays in the Upper West region. Majority (80\%) of the sample indicated their children were delivered in a health facility.

Results in Table 2 show the higher the level of education among males, the more children delivered in a health facility. For instance, men with a higher level of education had the majority (95\%) of their children delivered in a health facility, compared to children of males with no formal education (60\%). Christian (84.93\%), Islamic (74.23\%), and males of "Other" $(72.53 \%)$ religious belonging have more children delivered in a health facility. Males of Akan (87.56\%), Ga/Dangme (84.13\%), and Ewe (83.54\%) ethnic origins have more than three quarters of children delivered in a health facility. In terms of marital status, males not in union (single) or formerly married have the highest number of children (92.17 and $91.95 \%$, respectively) delivered in a health facility. Urban dwelling males have the most children (95.12\%) delivered in a health facility. Majority of males who reside in the Upper East (94.44\%), Greater Accra (93.86\%), and Ashanti $(91.48 \%)$ regions have most of the children born in a health facility whilst males resident in the Northern region have the least $(49.75 \%)$ of children delivered in a health facility.

To ascertain how well male presence determines the choice for a health facility as a place for child delivery, a single predictor binary logistic regression was fitted. Results shown in Table 3 indicate males not present at ANC are less likely (0.085) compared to those present at ANC to have children delivered in a health facility. A second model fitted introduced sociodemographic factors of males as control variables with the results shown in Table 4. From the Table, males within the age groups 25-34 (2.647), 35-44 (3.046), or 45-59 (3.513) are more likely to have their children delivered in a health facility compared to children of males within the age bracket $15-24$ years. Males with a higher level of education (4.478) are more likely than males with no education to have their children delivered in a health facility.

Males who belong to the Traditional/Spiritualist religion are less likely (0.473) than their Christian counterparts to have children delivered in a health facility. Mole-Dagbani or "Other"
TABLE 1 | Percentage distribution of respondents background characteristics.

\begin{tabular}{|c|c|c|}
\hline Variables & Frequency & Percentage (\%) \\
\hline & 1,139 & 100.00 \\
\hline \multicolumn{3}{|l|}{ PRESENT AT ANC } \\
\hline Yes & 494 & 43.4 \\
\hline No & 645 & 56.6 \\
\hline \multicolumn{3}{|l|}{ AGE } \\
\hline $15-24$ & 56 & 5 \\
\hline $25-34$ & 457 & 40.1 \\
\hline $35-44$ & 453 & 39.8 \\
\hline $45-59$ & 172 & 15.1 \\
\hline \multicolumn{3}{|c|}{ EDUCATIONAL LEVEL } \\
\hline No education & 215 & 18.9 \\
\hline Primary & 153 & 13.4 \\
\hline Secondary & 657 & 57.6 \\
\hline Higher & 114 & 10 \\
\hline \multicolumn{3}{|l|}{ RELIGION } \\
\hline Christians & 758 & 66.6 \\
\hline Islam & 261 & 22.9 \\
\hline Traditional/spiritualist & 57 & 5 \\
\hline No religion & 63 & 5.5 \\
\hline \multicolumn{3}{|l|}{ ETHNICITY } \\
\hline Akan & 508 & 44.6 \\
\hline Ga/Dangme & 65 & 5.7 \\
\hline Ewe & 143 & 12.5 \\
\hline Mole-Dagbani & 225 & 19.7 \\
\hline Other & 199 & 17.5 \\
\hline \multicolumn{3}{|l|}{ MARITAL STATUS } \\
\hline Not in union & 33 & 2.9 \\
\hline In union & 1084 & 95.2 \\
\hline Formerly in union & 22 & 1.9 \\
\hline \multicolumn{3}{|c|}{ PLACE OF RESIDENCE } \\
\hline Urban & 543 & 47.7 \\
\hline Rural & 596 & 52.3 \\
\hline \multicolumn{3}{|c|}{ REGION OF RESIDENCE } \\
\hline Western & 119 & 10.5 \\
\hline Central & 120 & 10.5 \\
\hline Greater accra & 203 & 17.8 \\
\hline Volta & 88 & 7.7 \\
\hline Eastern & 93 & 8.1 \\
\hline Ashanti & 196 & 17.2 \\
\hline Brong-Ahafo & 114 & 10 \\
\hline Northern & 132 & 11.6 \\
\hline Upper east & 46 & 4 \\
\hline Upper west & 29 & 2.6 \\
\hline \multicolumn{3}{|l|}{ PLACE OF BIRTH } \\
\hline Health facility & 915 & 80.3 \\
\hline Other & 224 & 19.7 \\
\hline
\end{tabular}

Source, Computed from GDHS 2014 male data file.

males compared to Akan males are less likely (0.400 and 0.425, respectively) to have children delivered in a health facility.

The never married males are more likely (5.682) than married males to have children delivered in a health institution. Males 
TABLE 2 | Percentage distribution of respondents by place of delivery, presence at $\mathrm{ANC}$, and background characteristics.

\begin{tabular}{|c|c|c|c|c|}
\hline \multirow[t]{2}{*}{ Background characteristics } & \multicolumn{2}{|c|}{ Place of delivery } & \multicolumn{2}{|c|}{ Number of men } \\
\hline & $\begin{array}{l}\text { Health facility } \\
\qquad(\%)\end{array}$ & $\begin{array}{c}\text { Others } \\
(\%)\end{array}$ & Freq & $\%$ \\
\hline \multicolumn{5}{|l|}{ PRESENT AT ANC } \\
\hline Yes & 82.8 & 17.2 & 493 & 100 \\
\hline No & 78.4 & 21.6 & 645 & 100 \\
\hline \multicolumn{5}{|l|}{$\chi^{2}$-value $=3.3850 ; P=0.1593$} \\
\hline \multicolumn{5}{|l|}{ AGE } \\
\hline $15-24$ & 69.7 & 30.3 & 56 & 100 \\
\hline $25-34$ & 80.8 & 19.2 & 457 & 100 \\
\hline $35-44$ & 80.9 & 19.1 & 453 & 100 \\
\hline $45-59$ & 81.0 & 19.0 & 172 & 100 \\
\hline \multicolumn{5}{|l|}{$\chi^{2}$-value $=4.3368 ; P=0.3666$} \\
\hline \multicolumn{5}{|l|}{ EDUCATIONAL LEVEL } \\
\hline No education & 60.1 & 39.9 & 215 & 100 \\
\hline Primary & 74.9 & 25.1 & 153 & 100 \\
\hline Secondary & 85.6 & 14.4 & 656 & 100 \\
\hline Higher & 95.3 & 04.7 & 114 & 100 \\
\hline \multicolumn{5}{|l|}{$\chi^{2}$-value $=88.5058 ; P<0.001$} \\
\hline \multicolumn{5}{|l|}{ RELIGION } \\
\hline Christians & 84.9 & 15.1 & 758 & 100 \\
\hline Islam & 74.2 & 25.8 & 260 & 100 \\
\hline Traditional/Spiritualist & 55.1 & 44.9 & 57 & 100 \\
\hline Other & 72.5 & 27.5 & 63 & 100 \\
\hline \multicolumn{5}{|l|}{$\chi^{2}$ value $=42.5568 ; P=0.0001$} \\
\hline \multicolumn{5}{|l|}{ ETHNICITY } \\
\hline Akan & 87.6 & 12.4 & 508 & 100 \\
\hline Ga/Dangme & 84.1 & 15.9 & 65 & 100 \\
\hline Ewe & 83.5 & 16.5 & 143 & 100 \\
\hline Mole-Dagbani & 72.7 & 27.3 & 224 & 100 \\
\hline Other & 66.8 & 33.2 & 199 & 100 \\
\hline \multicolumn{5}{|l|}{$\chi^{2}$ value $=50.8452 ; P=0.0001$} \\
\hline \multicolumn{5}{|l|}{ MARITAL STATUS } \\
\hline Not in union & 92.2 & 07.8 & 33 & 100 \\
\hline In union & 79.7 & 20.3 & 1084 & 100 \\
\hline Formerly in union & 91.9 & 08.1 & 22 & 100 \\
\hline \multicolumn{5}{|l|}{$\chi^{2}$ value $=5.1669 ; P=0.0390$} \\
\hline \multicolumn{5}{|l|}{ PLACE OF RESIDENCE } \\
\hline Urban & 95.1 & 04.9 & 543 & 100 \\
\hline Rural & 66.8 & 33.2 & 596 & 100 \\
\hline \multicolumn{5}{|l|}{$\chi^{2}$ value $=147.5551 ; P<0.001$} \\
\hline \multicolumn{5}{|l|}{ REGION OF RESIDENCE } \\
\hline Western & 77.7 & 22.3 & 119 & 100 \\
\hline Central & 77.8 & 22.2 & 120 & 100 \\
\hline Greater Accra & 93.9 & 06.1 & 203 & 100 \\
\hline Volta & 79.3 & 20.7 & 88 & 100 \\
\hline Eastern & 74.6 & 25.4 & 93 & 100 \\
\hline Ashanti & 91.5 & 08.5 & 196 & 100 \\
\hline Brong Ahafo & 78.4 & 21.6 & 114 & 100 \\
\hline Northern & 49.8 & 50.2 & 132 & 100 \\
\hline Upper East & 94.4 & 05.6 & 46 & 100 \\
\hline Upper West & 77.3 & 22.7 & 29 & 100 \\
\hline \multicolumn{5}{|l|}{$\chi^{2}$-value $=129.3370 ; P<0.001$} \\
\hline \multirow[t]{2}{*}{ Total } & 915 & 224 & 1139 & \\
\hline & 80.3 & 19.7 & & 100 \\
\hline
\end{tabular}

Computed from GDHS 2014 male data file.
TABLE 3 | Binary logistic regression model showing the association between male presence at ANC and health facility delivery.

\begin{tabular}{lcccc}
\hline Variable & \multicolumn{1}{c}{ Odds ratio } & S.E & $95 \%$ & CI \\
\hline MALE PRESENT AT ANC & & & \\
Present (RC) & 1.000 & & & \\
Not present & $0.085^{\star}$ & 0.144 & -0.198 & 0.368 \\
\hline$*<0.05$. Computed from the GDHS 2014 male data file. & &
\end{tabular}

residing in urban areas compared to those in the rural areas are 7.272 more likely to have children delivered in a health facility. Compared to males in the Greater Accra region, males resident in the Upper East region are 11.515 more likely to have children delivered in a health facility.

\section{DISCUSSION}

This study contributes to literature on male participation in maternal and child health in the Ghanaian context using the 2014 Ghana Demographic and Health Survey. Generally, result indicates male presence at ANC did not determine the choice of place of child delivery, contrary to the expectation that when males accompany spouses to ANC the health facility will be the place of choice for delivery. However, findings among Kenyans and Indians indicate a higher facility delivery among women whose male partners were present during ANC attendance [(15), p. 375; (16), p. 143]. Probably because it is not an integral part of the Ghanaian setting for husbands to be involved in their wife's ANC or their maternal health issues. In the Ghanaian society, men are congratulated and praised upon the conception of their spouses but rarely expected to be involved in issues concerning the pregnancy. Issues concerning pregnancies are considered a woman's business and not of concern to the man. This may explain why a man's presence during ANC is not a determinant of choice of place of child delivery.

Increasing age is found to predict the choice of health facility as a place of delivery. This is contrary to findings from Myanmar [(17), p. 6] and Indonesia [(18), p. 1,206]. Age is correlated to maturity as such within the Ghanaian setting, with increasing age, males may have observed outcomes from facility and out of facility delivery. This may have influenced their inclination toward a facility based delivery.

Level of education specifically higher education was found significant in predicting a health facility as a choice of place for delivery. Formal education is expected to make individuals much more knowledgeable on the merits of utilizing the maternal healthcare services which entails health facility delivery. The current study's finding about the positive effect of education on place of delivery corroborates an existing study $[(10,11)$, p. 3$]$. However, Danforth et al. [(13), p. 701] identified no relationship between the educational level of males and the choice of place of delivery.

Traditional/spiritualist males are found to be less likely to have their children delivered in a health facility. This is contrary to a finding by IIiyasu et al. [(19), p. 27] in Nigeria where religion 
TABLE 4 | Binary logistic regression analysis of association between ANC presence, socio-demographic characteristics, and delivery in health facility.

\begin{tabular}{|c|c|c|c|c|}
\hline Variable & Odds ratio & S.E & $95 \%$ & Cl \\
\hline \multicolumn{5}{|c|}{ MALE PRESENT AT ANC } \\
\hline Present (RC) & 1.000 & & & \\
\hline Not present & 1.197 & 0.239 & 0.808 & 1.773 \\
\hline \multicolumn{5}{|l|}{ AGE } \\
\hline $15-24(\mathrm{RC})$ & 1.000 & & & \\
\hline 25-34 & $2.647^{\star}$ & 1.041 & 1.221 & 5.736 \\
\hline $35-44$ & $3.046^{\star}$ & 1.266 & 1.345 & 6.896 \\
\hline $45-59$ & $3.513^{\star}$ & 1.546 & 1.478 & 8.345 \\
\hline \multicolumn{5}{|c|}{ EDUCATIONAL LEVEL } \\
\hline No education (RC) & 1.000 & & & \\
\hline Primary & 1.179 & 0.378 & 0.628 & 2.214 \\
\hline Secondary & 1.379 & 0.449 & 0.727 & 2.618 \\
\hline Higher & $4.478^{\star}$ & 2.628 & 1.412 & 14.199 \\
\hline \multicolumn{5}{|l|}{ RELIGION } \\
\hline Christian (RC) & 1.000 & & & \\
\hline Islam & 0.947 & 0.344 & 0.463 & 1.934 \\
\hline Traditional/spiritualist & $0.473^{\star}$ & 0.167 & 0.237 & 0.946 \\
\hline No religion & 0.647 & 0.195 & 0.358 & 1.169 \\
\hline \multicolumn{5}{|l|}{ ETHNICITY } \\
\hline Akan (RC) & 1.000 & & & \\
\hline Ga/Dangme & 0.505 & 0.266 & 0.179 & 1.424 \\
\hline Ewe & 0.653 & 0.224 & 0.333 & 1.281 \\
\hline Mole-Dagbani & $0.400^{\star}$ & 0.160 & 0.182 & 0.877 \\
\hline Other & $0.425^{\star}$ & 0.170 & 0.194 & 0.935 \\
\hline \multicolumn{5}{|l|}{ MARITAL STATUS } \\
\hline Never in union & $5.682^{\star}$ & 2.885 & 2.093 & 15.421 \\
\hline In union (RC) & 1.000 & & & \\
\hline Formerly in union & $5.669^{\star}$ & 3.935 & 1.448 & 22.198 \\
\hline \multicolumn{5}{|c|}{ PLACE OF RESIDENCE } \\
\hline Urban & $7.272^{\star}$ & 2.003 & 4.231 & 12.499 \\
\hline Rural (RC) & 1.000 & & & \\
\hline \multicolumn{5}{|c|}{ REGION OF RESIDENCE } \\
\hline Western & 0.617 & 0.351 & 0.201 & 1.888 \\
\hline Central & 0.599 & 0.372 & 0.176 & 2.035 \\
\hline Greater Accra (RC) & 1.000 & & & \\
\hline Volta & 0.806 & 0.473 & 0.254 & 2.558 \\
\hline Eastern & 0.537 & 0.271 & 0.199 & 1.447 \\
\hline Ashanti & 1.710 & 1.092 & 0.487 & 6.003 \\
\hline Brong-Ahafo & 0.716 & 0.405 & 0.236 & 2.175 \\
\hline Northern & 0.460 & 0.282 & 0.138 & 1.536 \\
\hline Upper East & $11.515^{*}$ & 8.312 & 2.785 & 47.618 \\
\hline Upper West & 2.125 & 1.376 & 0.595 & 7.591 \\
\hline${ }^{\star}<0.05$ & $=0.38$ & & & \\
\hline
\end{tabular}

Source, Computed from GDHS 2014 data file.

was not found to predict delivery in a health facility. People who profess this religion are adherents to traditional ways of life and are opposed to almost everything modern and what it brings. They are more in support of the use of herbs and traditional birth attendants, among others. They are thus more likely then to prefer delivery in their own home or the home of others such as that of a medicine man or woman.

In terms of ethnicity, males belonging to Mole-Dagbani or "Other" ethnic groups were found to be less likely to have their children delivered in a health institution. Similarly, a study by IIiyasu et al. [(19), p. 27] also found ethnic variation among ethnic groups in Nigeria. The various ethnic groups have different social and cultural practices in relation to childbirth which are practiced by the individual group members. This most likely may affect the choice of place of delivery.

Males who had never married were found to have a higher likelihood of having children delivered in a health facility. Study by IIiyasu et al. [(19), p. 27] found the marital status of male partners insignificant in the choice of a health facility for child delivery in Nigeria. Probably, as parents who are not married, they are independent in decision making regarding the pregnancy and ultimately the choice of delivery place. Urban residence among males is also associated with facility delivery. This is consistent with a study by Kurniati et al. [(18), p. 1,206] who also found urban residence associated with facility delivery in Indonesia. This may be explained by the fact that urban areas are clustered with both public and private health facilities in addition to ease of transportation. In addition, health facility delivery maybe an urban lifestyle compared to a home based delivery.

The region in which respondents' dwell in affects the place of child delivery as men in the Upper East region have more children delivered in a health facility. This may be explained by the presence of the Demographic and Health Surveillance System (DHSS) in the region as a result individuals are prompted to seek health care. Additionally, the region because of the DHSS has been the first to receive several interventions such as Community and Health Planning Services (CHPS) which has brought health services closer to the populace.

In terms of limitations, findings and conclusions are based on self-reports of respondents other than objective measures, as responses may have been influenced by social desirability. Also, causality cannot be established due to the cross-sectional nature of the data.

In conclusion, the study has shown that although male presence has no association with choice of place of child delivery, male background factors determine the choice of place for child delivery. In the face of efforts to improve maternal and child health, males need to be largely involved in governmental efforts.

\section{Policy Implication}

The identification of male background characteristics to determine the choice of place of child delivery indicates males should be involved in maternal health issues. The identified background factors should be considered in all maternal and child health related policy interventions. For instance, given the fact that education is vital to the choice of place of delivery, there is the need to promote and intensify health education in men with no formal education or less than a higher level of education. Secondly, considering the variation in religion, marital status, ethnicity, place, and region of residence regarding choice of place of delivery, specific tailored interventions must be formulated 
to address these variations. Interventions could consider how to integrate these factors into policies or as a leveraging tool to increase institutional delivery.

\section{DATA AVAILABILITY STATEMENT}

Data used for the study is available upon request from Measure DHS.

\section{ETHICS STATEMENT}

This study made use of the Ghana Demographic and Health Survey (GDHS 2014) and no mention was made of the IRB that granted ethical approval.

\section{REFERENCES}

1. WHO. Maternal Mortality. (2018). Available online at: http://www.who.int/ news-room/fact-sheets/detail/maternal-mortality (accessed November 27, 2018)

2. WHO. Millennium Development Goals (MDGs) (2013).

3. UNFPA. Good Practices Ghana Country Office 5th Country Program. (CP5) 2006-2011: Male Involvement in Sexual and Reproductive Health. Evidence and Action, Special Issue (2012).

4. Ijadunola MY, Abiona TC, Ijadunola KT, Afolabi OT, Esimai OA, OlaOlorun FM. Male involvement in family planning decision making in lle-lfe, Osun State, Nigeria. Afr J Reprod Health. (2010) 14:43-50.

5. Mrisho M, Schellenberg JA, Mushi AK, Obrist B, Mshinda H, Tanner M, et al. Factors affecting home delivery in rural Tanzania. Trop Med Int Health. (2007) 12:862-72. doi: 10.1111/j.1365-3156.2007.01855.x

6. Cohen SI, Burger M. Partnering: A New Approach to Sexual and Reproductive Health. New York, NY: United Nations Population Fund [UNFPA] (Technical Paper No. 3) (2010). p. 181.

7. USAID (2009). Country Health Statistical Report: Nigeria. Washington, DC.

8. Babalola S, Fatusi A. Determinants of use of maternal health services in Nigeria - looking beyond individual and household factors. BMC Pregnency Childbirth. (2009) 9:43:1-13. doi: 10.1186/1471-2393-9-43

9. Warren CE. Care seeking for maternal health: challenges remain for poor women. Ethiop J Health Dev. (2010) 24:100-4. doi: 10.4314/ejhd.v24i1.62950

10. Rai RK, Singh PK, Singh L. Utilization of maternal health care services among married adolescent women: insights from the nigeria demographic and health survey 2008. Women's Health Issues. (2012) 22:e407-14. doi: 10.1016/j.whi.2012.05.001

11. Craymah JP, Oppong RK, Tuoyire DA. Male involvement in maternal health care at anomabo, central region, Ghana. Int J Reprod Med. (2017) 2017:1-8. doi: 10.1155/2017/2929013

12. Carter MW, Speizer I. Salvadoran fathers' attendance at prenatal care, delivery, and postpartum care. Rev Panam Salud Publica. (2005) 18:149-56. doi: 10.1590/S1020-49892005000800001

\section{AUTHOR CONTRIBUTIONS}

PD conceived the study, run the analysis, wrote, and finalized the manuscript for submission.

\section{ACKNOWLEDGMENTS}

I wish to acknowledge Ghana Statistical Service and Measure DHS for the data use. The author would also like to express her sincere thanks to the Queen Elizabeth Advanced Scholars Program (QES) 2019 of the Queen's University, Kingston, Ontario, Canada for sponsoring the article processing charge (APC).

13. Danforth EJ, Kruk ME, Rockers PC, Mbaruku G, Galea S. Household decisionmaking about delivery in health facilities: evidence from Tanzania. J Health Popul Nutr. (2009) 27:696-703. doi: 10.3329/jhpn.v27i5.3781

14. Ghana Statistical Service (GSS), Ghana Health Service (GHS), and ICF International. Ghana Demographic and Health Survey 2014. Rockville, MD: GSS, GHS, and ICF International (2015).

15. Mangeni JN, Mwangi A, Mbugua S, Mukthar VK. Male involvement in maternal healthcare as a determinant of utilisation of skilled birth attendants in Kenya. East Afr Med J. (2012) 89:372-83.

16. Chattopadhyay A. Men in maternal care: evidence from India J Biosoc Sci. (2012) 44:129-53. doi: 10.1017/S00219320110 00502

17. Ampt F, Mon MM, Than KK, Khin MM, Agius PA, Morgan C, et al. Correlates of male involvement in maternal and newborn health: a cross-sectional study of men in a peri-urban region of Myanmar. BMC Pregnancy Childbirth. (2015) 15:122-32. doi: 10.1186/s12884-0150561-9

18. Kurniati A, Chen CM, Efendi F, Elizabeth Ku LJ, Berliana SM. Suami SIAGA: male engagement in maternal health in Indonesia. Health Policy Plann. (2017) 32:1203-11. doi: 10.1093/heapol/czx073

19. Iliyasu Z, Abubakar IS, Galadanci HS, Aliyu MH. Birth preparedness, complication readiness and fathers' participation in maternity care in a northern Nigerian community. Afr J Reprod Health. (2010) 14:21-32.

Conflict of Interest: The author declares that the research was conducted in the absence of any commercial or financial relationships that could be construed as a potential conflict of interest.

Copyright (C) 2019 Doegah. This is an open-access article distributed under the terms of the Creative Commons Attribution License (CC BY). The use, distribution or reproduction in other forums is permitted, provided the original author $(s)$ and the copyright owner(s) are credited and that the original publication in this journal is cited, in accordance with accepted academic practice. No use, distribution or reproduction is permitted which does not comply with these terms. 